\title{
EXAPTAÇÃO DA GESTÃO DE CITAÇÕES NA EMISSÃO DE PARECER: DISCUSSÃO DE BARREIRAS SOCIAIS PELO POLICY DELPHI
}

\section{EXAPTATION OF CITATION MANAGEMENT IN THE ISSUING OF OPINIONS: A DISCUSSION ON SOCIAL BARRIERS THROUGH THE POLICY DELPHI}

\section{EXAPTACIÓN DE LA GESTIÓN DE CITAS EN LA EMISIÓN DE PARECER: DISCUSIÓN DE BARRERAS SOCIALES MEDIANTE EL DELPHI DE POLÍTICAS}

\section{RESUMO}

Esta pesquisa aborda o desafio dos servidores públicos brasileiros de se manterem atualizados em relação ao complexo e crescente ambiente de documentos legais e normativos, com o propósito de atuarem eficazmente na análise e emissão de parecer em órgãos públicos. Utilizando a técnica Policy Delphi, discutem-se a exaptação da abordagem de gestão de citações e as referências da academia científica para o contexto da análise e emissão de pareceres em órgãos públicos. Por meio dos ciclos de interações do Policy Delphi com especialistas em gestão pública brasileira, analisaram-se as possíveis fontes de resistência à adoção da abordagem, bem como as políticas voltadas à sua inibição ou redução.

PALAVRAS-CHAVE: Fundamentação, parecer, exaptação, Policy Delphi, resistência.

José Osvaldo de Sordi ${ }^{1}$

osdesordi@gmail.com

Manuel Meireles ${ }^{2}$

meireles@faccamp.br

Carlos Rigato ${ }^{3}$

carlosrigato@yahoo.com.br

Milton Chagas ${ }^{4}$

morichagas@uol.com.br

Submetido 21.02.2017. Aprovado 28.12.2017

Avaliado pelo processo de double blind review.

DOI: http://dx.doi.org/10.12660/cgpc.v23n74.66375

${ }^{1}$ Centro Universitário das Faculdades Metropolitanas Unidas, Programa de Pós-graduação em Administração, São Paulo, SP, Brasil

${ }^{2}$ Instituto de Ensino Campo Limpo Paulista, Campo Limpo Paulista, SP, Brasil

${ }^{3}$ Universidade Anhembi Morumbi, São Paulo, SP, Brasil

${ }^{4}$ Instituto Nacional de Pesquisas Espaciais, São José dos Campos, SP, Brasil 


\section{Abstract}

This study addresses the challenge facing Brazilian public servants to keep up to date with the complex, growing framework of legal and normative documents, so as to conduct effective analyzes and issue opinions in government agencies. Using the Policy Delphi technique, we discuss the exaptation of the scholarly citation and reference management approach to the context of analyzes and issuing of opinions in government agencies. Through Policy Delphi's iteration cycles with Brazilian public management experts, we analyze the possible sources of resistance to the adoption of this approach, as well as policies that can inhibit or reduce it.

Keywords: Foundation, issuing of opinion, exaptation, Policy Delphi, resistance.

\section{Resumen}

Esta investigación aborda el desafío de los servidores públicos brasileños para mantenerse actualizados con relación al complejo y creciente ambiente de documentos legales y normativos, con el propósito de actuar eficazmente en el análisis y emisión de pareceres en órganos públicos. Utílizando el estudio Delphi de políticas, se discute la exaptación del enfoque de gestión de citas y referencias de la academia científica para el contexto del análisis y emisión de pareceres en órganos públicos. A través de los ciclos de interacciones del Delphi de politicas con especialistas en gestión pública brasileña, se analizaron las posibles fuentes de resistencia a la adopcion del enfoque, as í como políticas dirigidas a su inhibición o reducción.

Palabras clave: Fundamentación, parecer, exaptación, Delphi de políticas, resistencia.

\section{INTRODUÇÃO}

Entre 2000 e 2010, criaram-se 75.517 leis no Brasil, considerando-se as legislações ordinárias e complementares, estaduais e federais, além dos decretos federais. Têm-se 6.865 novas leis por ano ou 18 leis por dia (Duarte \& Otavio, 2011). Ao analisar 0 regramento das leis na forma de normas, constata-se que há um contingente ainda maior de documentos a serem considerados pelos analistas que atuam em órgãos públicos. A área tributária brasileira é um bom exemplo do excesso. No período de 1988 a 2013, geraram-se 4.785.194 normas tributárias, considerando-se as emanadas pelo governo federal, Estados da união e municípios (Amaral, Olenike \& Amaral, 2013). Esse ritmo acelerado de crescimento resulta no imbricamento de leis e na geração de antinomias, permitindo múltiplas interpretações das leis, inclusive entre os especialistas e cientistas da área do Direito (Ribeiro, 2011). Essa proliferação de normas torna o processo de compreensão e a aplicação delas em algo bastante complexo e desafiador:

Uma empresa de médio porte gasta em média 2.600 horas para compreensão dos regulamentos tributários e averiguação da sua conformidade fiscal, quase cinco vezes a média regional [dos países latino-americanos]. Entretanto, a existência de múltiplas autoridades fiscais leva à incerteza sobre a forma como a lei se aplica (Brazilian, 2011, p. 1, tradução nossa).

Esse cenário de excesso e de crescimento 
contínuo de documentos legais e normativos, muitas vezes contraditórios, configura um ambiente complexo e problemático aos analistas que atuam em órgãos públicos brasileiros. Para o desempenho de suas atividades-fim, de análise e consubstanciação de pareceres, são necessários o acompanhamento e a compreensão dos diversos documentos legais e normativos pertinentes aos objetos de interesses associados ao órgão público ao qual estão vinculados. Dificuldade similar é a vivenciada pelos pesquisadores: manterem-se atualizados sobre os avanços científicos de suas áreas, ou seja: acompanhar as publicações de diversas fontes acadêmicas-científicas, com o propósito de conduzir pesquisas atuais que propiciem avanços científicos efetivos.

No ambiente acadêmico-científico, o trabaIho intensivo dos pesquisadores em manterem-se atualizados e fazerem uso das mais recentes publicações de sua área tem sido auxiliado por diversos softwares. O Quadro 1 descreve algumas dessas tecnologias que apoiam as diversas atividades recursivas do processo da pesquisa científica: identificação e compreensão de novas publicações, utilização delas por intermédio de citações, criação de conhecimento científico, estruturação do novo conhecimento na forma de artigo e publicação do conhecimento. $\mathrm{O}$ ato de criação, caracterizado pela patente ou pelo artigo, faz do pesquisador um exemplo típico de knowledge worker. De forma contrária, o analista de órgão público não busca criar conhecimento, mas aplicar o já existente no exercício de suas funções, ou seja, citar e referenciar leis, normas e portarias em seus pareceres. As atividades necessárias para se manterem constantemente atualizados com as mais recentes normas, portarias e leis, a fim de aplicá-las no contexto da sua função, caracterizam os analistas de órgão públicos como information worker. 
José Osvaldo de Sordi - Manuel Meireles - Carlos Rigato - Milton Chagas

Quadro 1. Tecnologias em apoio às funções críticas da abordagem proposta

\begin{tabular}{|c|}
\hline $\begin{array}{l}\text { Repositório Institucional (RI) - sistema de informação que auxilia as organizações a colecionarem, } \\
\text { administrarem, distribuírem e conservarem seus ativos digitais. As estruturas de dados referentes aos } \\
\text { metadados destes ativos digitais são codificadas em XML seguindo o padrão Dublin Core. Entre os } \\
\text { vários free open source softwares RI destacam-se: DSpace (http://www.dspace.org), EPrints } \\
\text { (http://www.eprints.org), e Fedora (http://www.fedoracommons.org). }\end{array}$ \\
\hline $\begin{array}{l}\text { Dublin Core Metadata Initiative (DCMI) - conjunto de termos utilizados para descrever ativos } \\
\text { digitais ou físicos, ou seja, define padrão para metadados. Desta forma ele funciona como um protocolo } \\
\text { que facilita a indexação, divulgação e localização de conteúdos disponíveis nos diversos RI. Esse padrão } \\
\text { é endossado por normas da ISO (15836-2009), IETF RFC (5013) e NISO (Z39.85). }\end{array}$ \\
\hline $\begin{array}{l}\text { Open Archives Initiative Protocol for Metadata Harvesting (OAI-PMH) - é um protocolo } \\
\text { desenvolvido para coletar registros com a descrição de metadados no padrão DCMI. A denominação de } \\
\text { colheitadeira (harvesting) é em função da facilidade de coletar e juntar metadados de ativos digitais } \\
\text { provenientes de distintos RI, facilitando o desenvolvimento de grandes servidores de dados. Todo tramite } \\
\text { de dados se dá por intermédio das normas abertas do Hypertext Transport Protocol (HTTP) e Extensible } \\
\text { Markup Language (XML). }\end{array}$ \\
\hline $\begin{array}{l}\text { Servidor de dados (data providers) - entidade virtual que provê acesso livre aos metadados e, não } \\
\text { necessariamente, aos conteúdos. O OAI-PMH facilita a implementação dos servidores de dados. } \\
\text { Usuários finais não realizam pesquisas diretas nos servidores de dados, apenas via servidores de serviços } \\
\text { (service providers). Os RI contemplam entre outras coisas o servidor de dados para a armazenagem de } \\
\text { conteúdo. }\end{array}$ \\
\hline $\begin{array}{l}\text { Servidor de serviços (service providers) - usam as interfaces dos servidores de dados para coletar e } \\
\text { arquivar metadados. O envio da solicitação e as respostas ocorrem segundo os padrões do protocolo } \\
\text { OAI-PMH. Os RI contemplam entre outras coisas o servidor de serviços para distribuição e acesso de } \\
\text { conteúdo. }\end{array}$ \\
\hline $\begin{array}{l}\text { Software gerenciador de referências (SGR) - permite reunir os metadados de conteúdos relevantes } \\
\text { para um usuário, em um banco de dados pessoal de referências. Permite a inserção automática de textos } \\
\text { para o local desejado da citação, bem como da inserção dos dados necessários para compor uma inserção } \\
\text { do conteúdo citado na lista de referências do documento. Entre os SGR destacam-se: EndNote, Mendeley } \\
\text { e RefWorks. }\end{array}$ \\
\hline $\begin{array}{l}\text { Software gerenciador de taxionomia (taxionomy software) - permite classificar um documento a } \\
\text { partir da análise de strings de texto do conteúdo do documento. No contexto em questão, pode ser útil } \\
\text { para definir tipo de solicitação e tipo de parecer emitido: deferido ou indeferido. }\end{array}$ \\
\hline $\begin{array}{l}\text { Digital Object Identifier (DOI) - permite a identificação, localização e acesso de documentos na } \\
\text { Internet. Pode se atribuir um DOI a toda lei, norma, portaria e demais documentos relevantes às análises. }\end{array}$ \\
\hline $\begin{array}{l}\text { Indicador bibliométrico para utilização do documento - algoritmos de mensuração de citações por } \\
\text { documentos são amplamente difundidos. Entre esses algoritmos destaca-se o H-index de Hirsh (2005). }\end{array}$ \\
\hline
\end{tabular}

Embora as funções desempenhadas pelo pesquisador e pelo analista de órgãos públicos não sejam as mesmas, há muita pertinência e algumas funções em comum, em especial o reconhecimento de novos documentos e o uso deles em citações. Para essa abordagem de trabalho, contemplando diversas tecnologias e processos, pode se estabelecer um paralelo com os artefatos, conforme descrito na ciência do artificial (Simon, 1996). Ao analisar as oportunidades de exploração de artefatos pela aca- demia, Gregor e Hevner (2014) trabalharam uma tipologia centrada em duas dimensões: domínio do problema do usuário e domínio da solução tecnológica a ser empregada, conforme destacado na Figura 1. A possibilidade de trazer as práticas de trabalho dos pesquisadores para os analistas de órgãos públicos, implica trazer uma abordagem tecnológica conhecida e madura para um novo contexto, no qual se tem menor nível de conhecimento tanto do ambiente de negócios quanto dos futuros usuários. Esse cenário 
se caracteriza como um evento de exaptação, conforme definido por Gregor e Hevner (2014, p. 347): "exploração de artefatos de

Figura 1. Framework das contribuições da DSR um campo para resolver problemas em outro campo".

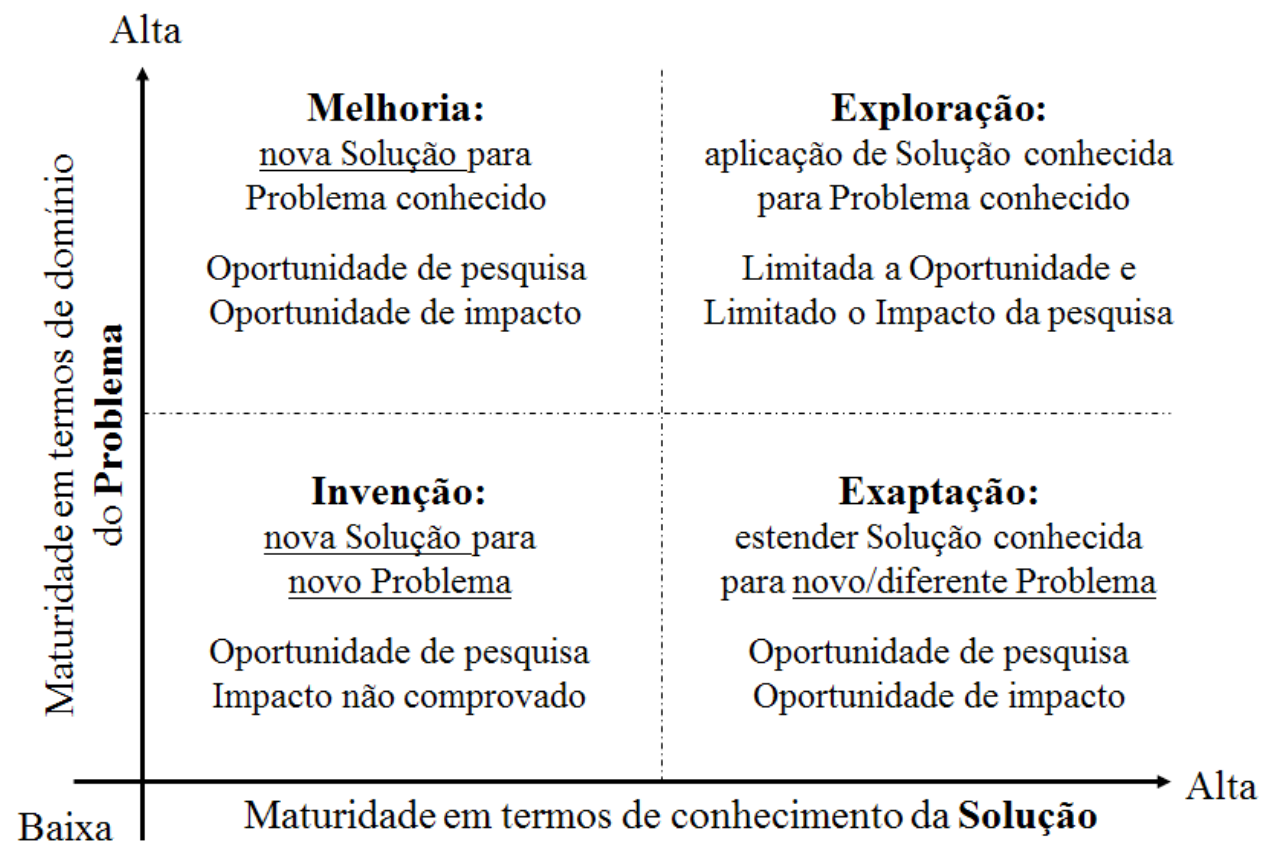

Fonte: Gregor e Hevner (2014:221)

Quanto aos riscos em projetos do tipo exaptação, eles podem ser melhores compreendidos pelo modelo de Danneels (2002), o qual apresenta uma estrutura muito similar ao modelo de Gregor e Hevner (2014), também apresentando quatro tipos de projetos inovadores, classificados segundo as dimensões tecnologia e demanda dos clientes: pure exploitation, leveraging customer competence, leveraging technological competence e pure exploration. O tipo de inovação "leveraging technological competence" é o que envolve alto nível de competências da empresa na dimensão tecnologia e pouco na dimensão demanda dos clientes, análogo ao tipo exaptation de Gregor e Hevner (2014). O modelo de Danneels (2002) indica nível de risco "relativamente incerto" para projetos dessa natureza, apresentando menor risco apenas com relação aos projetos "pure exploration", equivalente ao tipo invenção de Gregor e Hevner (2014). Como forma de mitigar o risco desse tipo de projeto, o modelo de Danneels (2002) indica como "necessário a pesquisa de mercado" junto ao novo segmento. Quanto à viabilidade tecnológica, a situação é indicada como "relativamente fácil". De forma semelhante aos modelos de Gregor e Hevner (2014) e de Danneels (2002), o modelo de Turner e Cochrane (1993) também aponta para um maior risco e cuidado para com os aspectos associados à demanda dos clientes, futuros usuários da abordagem.

A percepção da pertinência e viabilidade 
técnica da abordagem acadêmica para o ambiente da análise e emissão de parecer em órgãos públicos, bem como o maior risco associado às demandas do cliente para os projetos de exaptação direcionaram a atenção dessa pesquisa para questões associadas à dimensão demanda dos clientes (domínio do problema), em detrimento à dimensão tecnologia; ou seja, a melhor compreensão da demanda e das características dos analistas dos órgãos públicos, e das possíveis fontes de resistência deles à adoção da abordagem. Há de se destacar que o pesquisador propõe de forma espontânea e esporádica as suas contribuições (ato voluntário) na forma de artigo científico à comunidade científica, a ser avaliado por editores e referees. Já os analistas reportam (ato involuntário) suas opiniões sobre solicitações do dia a dia encaminhadas aos órgãos públicos por diversos atores sociais. Há, portanto, um alto nível de stress e controle social sob o trabalho desenvolvido pelos analistas de órgão público, configurando um contexto social e um ambiente de trabalho distinto do encontrado no ambiente acadêmico-científico.

Sendo a abordagem proposta dependente do uso de softwares pelos analistas de órgãos públicos, é importante destacar que a resistência a softwares é uma das principais causas de insucesso de projetos corporativos (O'Brien, 2004; Argyris, 1971). A maioria dos estudos de fontes de resistência aos softwares foi desenvolvido na década de 1970, na ocasião da expansão do emprego dos softwares para além da automação de atividades (sistemas batch) quando da introdução dos sistemas de informação gerenciais que demandam iteração homem-máquina para realização de transações por intermédio da iteração com os softwares. Argyris (1971) destaca quatro causas associadas à resistência ao uso de sistemas, sendo a "redução do espaço de circulação" uma delas. Barthol e Vasarhelyi (1975, p. 30), ao discutirem os riscos da implantação de sistemas de informação desenvolvidos no exterior, para o contexto das instituições brasileiras, contextualizaram a causa "redução do espaço de circulação" da seguinte forma:

O medo de ser descoberto não é, todavia, o mais importante fator de resistência. A grande maioria dos administradores opera dentro dos limites legais e, em ocorrendo situações inesperadas, podem destruir as provas incriminadoras que estejam sob seu controle. O que mais importa no caso, como fator de resistência, é o fato de o informal ou sub-reptício, quando tornado explícito, reverter ao controle formal da administração, limitando, acentuadamente, a ação de seus participantes. Nas palavras de Argyris, "o administrador experimenta uma redução no seu espaço de livre movimento, que o leva a sentir-se indefeso, incapaz de autodeterminar-se, circunstância capaz de fazê-lo retirar-se de cena ou tornar-se dependente. Ele pode sentir falta de alternativas, pressão e sentimentos de fracasso psicológico".

Além dos riscos associados à dimensão humana de projetos de exaptação e das fontes de resistência tradicionais a novos sistemas de informação, acrescenta-se o risco de ações de autodefesa do grupo de usuários associado à abordagem em questão. $\mathrm{O}$ corporativismo entre os funcionários públicos brasileiros (Cardoso, 2002; Felker, 2003) pode tornar-se um obstáculo a implementação da abordagem caso haja a percepção da 
geração de problemas ou de dificuldades à categoria. A partir desse cenário de riscos, a presente pesquisa tem como objetivo: analisar possíveis resistências políticas, culturais e sociais à abordagem proposta em apoio ao Processo de Análise e Emissão de Pareceres em Órgãos Públicos (PAEPOP), bem como discutir ações para inibir tais resistências. Para isso, aplicamos a técnica Policy Delphi, uma variante da técnica Delphi (Turoff, 1970). A finalidade da Policy Delphi é averiguar o consenso entre especialistas sobre as políticas que possam colaborar com o tema em análise (Critcher \& Gladstone, 1998). Sua operacionalização envolve a proposição de políticas por especialistas seguida de suas análises das dimensões importância e exequibilidade pelo grupo de especialistas (Valente, Castellani, Larsen \& Aro, 2015).

A relevância desta pesquisa se explica pela capacidade da abordagem proposta em gerar maior transparência e compreensão da lógica de raciocínio conduzida pelos analistas de órgãos públicos, fazendo do processo de citação e referência um instrumento de redução de erros de análises, inibição de atos ilícitos ou, pelo menos, um meio de auxílio à identificação de tais atos. Os resultados negativos da corrupção, caracterizados pela improdutividade com base na manipulação de comportamentos, proporcionam ineficiências para o mercado interno do país, além de inibir o fluxo de investimentos diretos de estrangeiros (Gupta, Davoodi \& Alonso-Terme, 1998). Destarte, caracteriza-se a importância de abordagens voltadas ao combate à corrupção, por mais pontuais e simplistas que possam ser a colaboração delas. Srivastava, Teo e Devaraj (2016) analisaram os resultados de 20 soluções de tecnologia da informação e comunicação voltadas ao combate à corrupção. Nenhuma delas se voltou à execução das atividades de análise e emissão de parecer, realizadas pelo analista, ou à conferência do parecer, feita pelo gestor, conforme discutiremos nesta pesquisa.

\section{QUESTÕES CONCEITUAIS E LEGAIS}

Este capítulo aborda a importância das atividades de citação e referência ao processo de gestão da informação nas organizações, em especial, a utilização das citações para identificar o uso de conteúdos pelos profissionais. Esse tema, no contexto do PAEPOP, torna-se imperativo como meio do analista, servidor público, em atender as exigências legais de sua função, pela fundamentação de seus pareceres por intermédio de citações a leis, normas, portarias e demais documentos.

Citação e referência em pareceres de órgãos públicos

As solicitações de pessoas físicas ou jurídicas junto aos órgãos públicos são processadas e analisadas por meio dos processos administrativos. $O$ processo administrativo é um encadeamento de atos, juridicamente ordenados, voltados à geração de decisão administrativa consubstanciada, que provê registro e controle dos comportamentos dos administrados e de seus servidores com o objetivo de compatibilizar os interesses público e privado (Gasparini, 2005). Como exemplos de solicitações que geram processos administrativos junto aos diferentes níveis de esferas públicas - federal, estadual e municipal -, têm-se: a) a solicitação da aprovação de um projeto de edificação junto 
à esfera municipal; b) a solicitação de laudo ambiental para um empreendimento industrial junto à esfera estadual; c) a solicitação de impugnação de lançamento tributário referente à importação junto à esfera federal.

Entre as exigências do processo administrativo, tem-se a obrigação de atender ao princípio da motivação. Teixeira (2009, p.1) define motivação no processo administrativo como:

[...] a explanação, a fundamentação, a explicitação dos motivos que conduziram o agente público para a elaboração do ato administrativo. Com esteio na lei 9784/99, Hely Lopes Meirelles diz que "denomina-se motivação a exposição ou a indicação por escrito dos fatos e dos fundamentos jurídicos do ato". Motivar significa apresentar e explicar, de maneira clara e congruente, os elementos que ensejaram o convencimento da autoridade, indicando os fatos e os fundamentos jurídicos que foram considerados.

Diversos artigos da Lei federal do Brasil que regula o processo administrativo no âmbito da Administração Pública Federal indicam a necessidade de fundamentação em vários momentos, em muitas das atividades do processo administrativo. Essa recorrência evidencia a importância da prática de citação e referência para o PAEPOP. No quarto capítulo da lei, que trata do início do processo administrativo, a lei indica a necessidade do requerente em fundamentar (citar e referenciar) sua solicitação (Brasil, 1999, grifo nosso):

Art. 6'O requerimento inicial do interessado, salvo casos em que for admitida solici- tação oral, deve ser formulado por escrito e conter os seguintes dados:

[...]

IV. formulação do pedido, com exposição dos fatos e de seus fundamentos;

No 12 ' capítulo da lei, que aborda a elaboração da Motivação, evidencia-se a necessidade da citação e referência por parte do analista do órgão público que elabora o parecer (Brasil, 1999, grifo nosso):

Art. 50' Os atos administrativos deverão ser motivados, com indicação dos fatos e dos fundamentos jurídicos [...]

A maioria dos Estados que compõem a República Federativa do Brasil apresentam leis específicas para regulação de seus processos administrativos, que abordam a necessidade de motivação de forma muito similar à lei federal. Como exemplo, cita-se a lei paulista que regula o processo administrativo no âmbito da administração pública estadual (São Paulo, 1998). No âmbito dos demais estados membros da República Federativa do Brasil, na ausência de lei própria que regule o processo administrativo no âmbito local, há entendimento do Supremo Tribunal de Justiça de estender e aplicar a lei federal nessas localidades (Brasil, 2010).

Importância da citação e referência no processo de gestão da informação

Lytras e Pouloudi (2003) consolidaram as atividades de processos de gestão da informação de 20 diferentes modelos. Eles se pautaram em trabalhos anteriores de Nissen, Kamel e Sengupta (2000), que consolidaram cinco dessas perspectivas, e de Rubenstein-Montano et al. (2001), que analisaram outras 
15 perspectivas. Lytras e Pouloudi (2003) destacaram um conjunto de atividades dominantes que se repetem na maioria dos modelos para gestão da informação: obter conteúdo, distribuir, utilizar, aprender com o uso, criar novos conteúdos, compartilhar o novo, avaliar e descartar conteúdo.

Segundo Choo (2011) a utilização da informação nas organizações ocorre em três arenas interconectadas: a) Criação de significado; b) Construção do conhecimento; c) Tomada de decisão. Choo (2011) destaca que a racionalidade da tomada de decisão pode ser atrapalhada pelo choque de interesses entre os sócios da empresa, pelas barganhas e negociações entre grupos e indivíduos, pelas limitações e idiossincrasias que envolvem as decisões, pela falta de informações, pelas limitações da capacidade da mente humana, entre outras razões. É importante destacar que a decisão nem sempre é racional e que está sujeita a erros. Nas decisões em órgãos públicos, como ocorre com os analistas responsáveis pela análise e emissão de pareceres, a implementação de um processo eficaz de gestão da informação pode auxiliar a evitar ou, pelo menos, indicar os desvios de racionalidade no processo de análise e tomada de decisão.

Apesar das dificuldades para mensuração da atividade "Utilizar conteúdo", essa é fundamental às organizações: "o conhecimento é percebido como residente internamente ao indivíduo e o papel principal da organização é a aplicação do conhecimento, ao invés da criação de conhecimento" (Grant, 1996, p. 109). No contexto do ambiente acadêmico-científico, o acompanhamento do uso e da eficácia dos documentos científicos se dá pelo processo de gestão das citações e referências feitas a eles; esta pesquisa propõe a exaptação dessa prática acadêmica-científica para o contexto da gestão pública, a qual permitirá analisar o uso dos documentos legais e normativos na elaboração da fundamentação de pareceres, como também evidenciará com mais profundidade e clareza o raciocínio empregado pelos analistas na elaboração da motivação de cada parecer. Essa situação gera uma tensão de controle positiva à qualidade das análises e dos pareceres, considerando que manterá os analistas atentos à necessidade de identificar e citar os documentos pertinentes à motivação que consubstanciará cada um dos pareceres.

Mathieson (2007, p. 286) afirma que abordagens do tipo Decision Support System "não podem nos dizer o que é certo, mas eles podem nos ajudar a pensar sobre isso". Afirma que os artefatos construídos com o paradigma de pesquisa Design Science Research (DSR) para "problemas associados à imoralidade" podem auxiliar na tomada de decisão ética, por exemplo, permitindo o registro histórico das análises realizadas e o reuso de boas análises. A implementação efetiva da abordagem, abrangendo funções como essas de registro e reuso, configura um instrumento capaz de influenciar os comportamentos dos analistas e a própria cultura dos órgãos públicos. Significa fazer uso do potencial estratégico de artefatos:

[...] os artefatos não constituem manifestações secundárias e superficiais de um fenômeno cultural mais profundo (Schein, 1984), mas constituem em um fenômeno cultural primário que influencia a vida corporativa com base em dois pon- 
tos de vista distintos: (a) artefatos tornam materialmente possível favorecer, obstruir ou mesmo prescrever a ação organizacional; (b) de forma mais geral, os artefatos influenciam nossa percepção da realidade, até o ponto de delinear, sutilmente, crenças, normas e valores culturais (Gagliardi, 2001, p. 132, grifo nosso).

Mathieson (2007) destaca a importância da aplicação de abordagens pragmáticas, como a exaptação de artefatos segundo a estratégia Design Science research, em termos de contribuição à tomada de decisão ética vinculada a "problemas associados à imoralidade":

Design science é particularmente apropriada a "problemas associados à imoralidade" (Chae et al., 2005; Hevner et al., 2004). Os problemas ligados à imoralidade são ambíguos, ocorrem em ambientes complicados e mal definidos e envolvem interação social (Mathieson, 2007, p. 270, tradução nossa).

A proliferação contínua de leis, normas e portarias, o ambiente corporativista entre os servidores públicos brasileiros e o sistema de rodízio de pares (analistas técnicos) na função de controle e supervisão dos pareceres emitidos pelo órgão configuram o PAEPOP em um ambiente propício à análise equivocada, de difícil percepção e penalização de seus autores, ou seja, bastante favorável à proliferação de "problemas associados à imoralidade".

\section{MÉTODO DA PESQUISA}

Para analisar a percepção de possíveis resistências políticas, culturais e sociais à abordagem proposta nesta pesquisa, aplicamos a técnica Policy Delphi, uma variante da técnica Delphi (Turoff, 1970). A finalidade da Policy Delphi é averiguar o consenso entre os especialistas sobre as políticas que possam colaborar com o tema em análise (Critcher \& Gladstone, 1998). Sua operacionalização envolve a proposta de políticas pelos especialistas, seguido da análise das dimensões importância e exequibilidade pelo grupo de especialistas (Valente, Castellani, Larsen \& Aro, 2015). Assim como na técnica Delphi, trabalha-se com o anonimato dos especialistas, que interagem via questionários e relatórios de feedback contendo as posições do grupo de especialistas. A cada ciclo de interação, o especialista tem a oportunidade de ler os pareceres e justificativas dos demais especialistas e reposicionar seu parecer, caso julgue pertinente. Definiram-se dois perfis de especialistas para o PAEPOP: a) funcionário público, com seis ou mais anos na função de analista, com responsabilidade pela emissão de pareceres junto a órgãos públicos; b) funcionário público ou cargo de confiança, com seis ou mais anos na função de gestor do PAEPOP.

Ao considerar que a inovação por exaptação apresenta como maior desafio as incertezas e os riscos comerciais e que o ambiente das empresas públicas demanda leis ou pelo menos normas para introdução de inovações, decidiu-se por estruturar as análises de possíveis fontes de resistência à abordagem proposta nesta pesquisa da seguinte forma:

a) Concentrar-se nos aspectos de aceitação comercial da abordagem discutindo as possíveis restrições políticas, culturais e sociais dos principais atores envolvidos: os analistas (servidores públicos) que atuam nos órgãos 
públicos;

b) Concentrar-se nas atividades centrais do processo, como as de análise e emissão de parecer, bem como nas atividades de supervisão e controle dos pareceres emitidos, ou seja, concentrar-se nos executores (analistas) e nos responsáveis pela qualidade dos trabalhos (gestores).

A pesquisa demandou três ciclos de iteração com os especialistas, conforme descrito no Quadro 2. No primeiro ciclo de interação, utilizou-se uma apresentação com animação automática do PowerPoint, com sete slides, para demonstrar as principais funções do PAEPOP suportadas pela abordagem em discussão, bem como expor as quatro questões iniciais descritas no Quadro 2. A apresentação utilizada como instrumento para essa primeira interação e coleta de dados está disponível em <www.datadelphi. com>. Ao término do primeiro ciclo, a quarta questão, permitiu coletar 37 proposições de políticas indicadas pelos especialistas como instrumentos para inibir ou reduzir as possíveis fontes de resistência dos analistas de órgãos públicos contra o uso da abordagem. O comando dessa quarta questão destacou a possibilidade de haver fontes de resistência em razão de os analistas se sentirem desconfortáveis com a capacidade da abordagem em permitir o acompanhamento e controle de suas análises. Com a análise dessas 37 proposições iniciais, observou-se que muitas eram similares. Após as atividades de categorização e consolidação delas, obtiveram-se 21 proposições, distribuídas em 5 categorias, que foram apresentadas para análise dos especialistas no segundo ciclo.

Quadro 2. Ações e resultados dos três ciclos de interação com os especialistas

\begin{tabular}{|c|c|c|c|c|}
\hline \multirow{2}{*}{\multicolumn{2}{|c|}{ Instrumento de Interação + Questões }} & $1^{\circ}$ Ciclo & $2^{\circ}$ Ciclo & $3^{\circ}$ Ciclo \\
\hline & & \multicolumn{3}{|c|}{ Ações Realizadas } \\
\hline \multirow{4}{*}{ 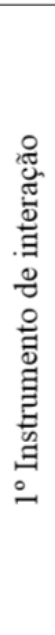 } & $\begin{array}{l}1^{\text {a }} \text { Questão analítica - do nível de } \\
\text { apoio do artefato aos Analistas } \\
\text { durante as atividades de análise e } \\
\text { emissão de parecer }\end{array}$ & $\begin{array}{l}\text { Coleta de } \\
\text { parecer }{ }^{[1]} \mathrm{e} \\
\text { obtenção de } \\
\text { consenso }\end{array}$ & & \\
\hline & $\begin{array}{l}2^{\text {a }} \text { Questão analítica - do nível de } \\
\text { apoio do artefato aos Gestores no } \\
\text { monitoramento e controle da } \\
\text { qualidade dos pareceres emitidos }\end{array}$ & $\begin{array}{l}\text { Coleta de } \\
\text { parecer }^{[1]} \mathrm{e} \\
\text { obtenção de } \\
\text { consenso }\end{array}$ & & \\
\hline & $\begin{array}{l}3^{\text {a }} \text { Questão analítica - do nível de } \\
\text { receptividade dos analistas de órgãos } \\
\text { públicos ao uso e aos resultados do } \\
\text { artefato }\end{array}$ & $\begin{array}{c}\text { Coleta de } \\
\text { parecer }{ }^{[2]} \mathrm{e} \\
\text { tabulação para } \\
\text { revisão }\end{array}$ & $\begin{array}{l}\text { Coleta de } \\
\text { parecer[2] e } \\
\text { tabulação para } \\
\text { revisão }\end{array}$ & $\begin{array}{l}\text { Coleta de } \\
\text { parecer[2] e } \\
\text { obtenção de } \\
\text { consenso }\end{array}$ \\
\hline & $\begin{array}{l}4^{\text {a }} \text { Questão para levantamento - de } \\
\text { proposições de ações para } \\
\text { inibir/reduzir possiveis fontes de } \\
\text { resistência ao artefato }\end{array}$ & $\begin{array}{l}\text { Identificação de } \\
\text { proposições e } \\
\text { categorização } \\
\text { detas }\end{array}$ & & \\
\hline 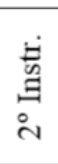 & $\begin{array}{l}21 \text { Questões - uma para cada } \\
\text { proposição, solicitando análise da } \\
\text { exequibilidade e importância no } \\
\text { combate à resistência }\end{array}$ & & $\begin{array}{l}\text { Coleta de } \\
\text { parecer }^{[3]} \mathrm{e} \\
\text { tabulação para } \\
\text { revisão }\end{array}$ & $\begin{array}{l}\text { Coleta de } \\
\text { Parecer }{ }^{[3]} \mathrm{e} \\
\text { obtenção de } \\
\text { consenso }\end{array}$ \\
\hline & Total de especialistas que interagiram & 13 & 10 & 10 \\
\hline \multicolumn{5}{|c|}{$\begin{array}{l}\text { [1] Resposta via escala Likert de cinco pontos, de "Totalmente inútil" a "Totalmente útil" } \\
\text { [2] Resposta via escala Likert de cinco pontos, de "Forte resistência" a "Forte apoio" } \\
\text { [3] Resposta via escala Likert de cinco pontos, de "Muito baixa" a "Muito alta", para as dimensões } \\
\text { Importância e Exequibilidade, para cada uma das } 21 \text { proposições apresentadas }\end{array}$} \\
\hline
\end{tabular}


Os três ciclos ocorreram entre setembro de 2016 e janeiro de 2017. A redução de 13 para 10 especialistas entre o primeiro e segundo ciclo se deve principalmente às dificuldades ocasionadas pelo final de mandato dos prefeitos, ocorrida nesse período e que demandou a participação de muitos dos profissionais da equipe de especialistas do Delphi em equipes de transição dos governos municipais. A equipe de dez especialistas no PAEPOP, que participaram dos três ciclos de interação da pesquisa, apresenta o seguinte perfil: gênero: 6 homens e 4 mulheres; vínculo com o órgão público, 7 servidores públicos concursados e 3 cargos de confiança; órgão público em que atua, 5 municipais, 3 estaduais e 2 federais; função no PAEPOP, 4 gestores e 6 analistas; escolaridade: todos portadores de diploma de nível superior.

A Policy Delphi, assim como no Delphi tradicional, envolve a análise de temas por um grupo de especialistas. Os procedimentos para avaliação das respostas fornecidas por eles dependem da finalidade do estudo, mas, geralmente, os "cálculos de dimensões únicas de médias e intervalos globais são suficientes para identificar o consenso" (Critcher \& Gladstone, 1998, p. 436). Um aspecto central das análises é a apuração do nível de consenso, bem como a da direção desse consenso: "a favor", "contra" ou "indiferente" para cada proposição analisada. Para atender a essa demanda, aplicou-se a escala de classificação de concordância (agreement rating scale), descrita e utilizada pela primeira vez por De Loë (1995) e refinada por O'Loughlin e Kelly (2004). O Quadro 3 apresenta os critérios e a lógica empregados para definir o nível de consenso, bem como a sua direção. 
Quadro 3. Critérios e lógica empregados na escala de classificação de concordância

\begin{tabular}{|c|c|c|c|c|}
\hline $\begin{array}{l}\text { Nivel de } \\
\text { Concordância } \\
\text { Alternativas } \\
\text { Respostas Likert }\end{array}$ & $\begin{array}{c}\text { ALTO } \\
\text { nível de consenso }\end{array}$ & $\begin{array}{l}\text { MODERADO } \\
\text { nível de consenso }\end{array}$ & $\begin{array}{c}\text { BAIXO } \\
\text { nível de consenso }\end{array}$ & $\begin{array}{c}\text { Direção do } \\
\text { consenso }\end{array}$ \\
\hline $\begin{array}{l}\text { "Concorda } \\
\text { Plenamente" } \\
\text { (CP) }\end{array}$ & $\begin{array}{l}70 \% \text { ou mais de } \\
\text { respostas na } \\
\text { alternativa } \mathrm{CP}\end{array}$ & $\begin{array}{l}60 \% \text { ou mais de } \\
\text { respostas na } \\
\text { alternativa } \mathrm{CP}\end{array}$ & $\begin{array}{l}50 \% \text { ou mais de } \\
\text { respostas na } \\
\text { alternativa } \mathrm{CP}\end{array}$ & \multirow{3}{*}{ A FAVOR } \\
\hline $\begin{array}{l}\text { "Concorda } \\
\text { Plenamente" + } \\
\text { "Concorda" } \\
(\mathrm{CP}+\mathrm{C})\end{array}$ & $\begin{array}{l}80 \% \text { ou mais de } \\
\text { respostas no } \\
\text { consolidado das } \\
\text { alternativas } \mathrm{CP}+\mathrm{C}\end{array}$ & $\begin{array}{l}70 \% \text { ou mais de } \\
\text { respostas no } \\
\text { consolidado das } \\
\text { alternativas } \mathrm{CP}+\mathrm{C}\end{array}$ & $\begin{array}{l}60 \% \text { ou mais de } \\
\text { respostas no } \\
\text { consolidado das } \\
\text { alternativas } \mathrm{CP}+\mathrm{C}\end{array}$ & \\
\hline "Concorda" (C) & $\begin{array}{l}70 \% \text { ou mais de } \\
\text { respostas na } \\
\text { alternativa C }\end{array}$ & $\begin{array}{l}60 \% \text { ou mais de } \\
\text { respostas na } \\
\text { alternativa C }\end{array}$ & $\begin{array}{l}50 \% \text { ou mais de } \\
\text { respostas na } \\
\text { alternativa C }\end{array}$ & \\
\hline $\begin{array}{l}\text { "Nem concordo, } \\
\text { nem discordo" } \\
(\mathrm{NN})\end{array}$ & $\begin{array}{l}70 \% \text { ou mais de } \\
\text { respostas na } \\
\text { alternativa NN }\end{array}$ & $\begin{array}{l}60 \% \text { ou mais de } \\
\text { respostas na } \\
\text { alternativa NN }\end{array}$ & $\begin{array}{l}50 \% \text { ou mais de } \\
\text { respostas na } \\
\text { alternativa NN }\end{array}$ & INDIFERENTE \\
\hline “Discorda" (D) & $\begin{array}{c}70 \% \text { ou mais de } \\
\text { respostas na } \\
\text { alternativa D }\end{array}$ & $\begin{array}{c}60 \% \text { ou mais de } \\
\text { respostas na } \\
\text { alternativa D }\end{array}$ & $\begin{array}{c}50 \% \text { ou mais de } \\
\text { respostas na } \\
\text { alternativa D }\end{array}$ & \multirow{3}{*}{ CONTRA } \\
\hline $\begin{array}{l}\text { "Discorda } \\
\text { Plenamente" + } \\
\text { "Discorda" } \\
(\mathrm{DP}+\mathrm{D})\end{array}$ & $\begin{array}{l}80 \% \text { ou mais de } \\
\text { respostas no } \\
\text { consolidado das } \\
\text { alternativas DP+D }\end{array}$ & $\begin{array}{l}70 \% \text { ou mais de } \\
\text { respostas no } \\
\text { consolidado das } \\
\text { alternativas DP+D }\end{array}$ & $\begin{array}{l}60 \% \text { ou mais de } \\
\text { respostas no } \\
\text { consolidado das } \\
\text { alternativas DP+D }\end{array}$ & \\
\hline $\begin{array}{l}\text { "Discorda } \\
\text { Plenamente" } \\
\text { (DP) }\end{array}$ & $\begin{array}{c}70 \% \text { ou mais de } \\
\text { respostas na } \\
\text { alternativa DP }\end{array}$ & $\begin{array}{c}60 \% \text { ou mais de } \\
\text { respostas na } \\
\text { alternativa DP }\end{array}$ & $\begin{array}{l}50 \% \text { ou mais de } \\
\text { respostas na } \\
\text { alternativa DP }\end{array}$ & \\
\hline
\end{tabular}

Fonte: Adaptado de O’Loughlin e Kelly (2004)

\section{DESCRIÇÃO DA ABORDAGEM}

Apresentamos nesta seção as atividades do processo de gestão da informação contextualizadas para o PAEPOP. Embora a atividade "Identificar conteúdo" tenha sido considerada por poucos autores que propuseram modelos de processos de gestão da informação (Lytras \& Pouloudi, 2003), consideramo-la como relevante ao contexto brasileiro em questão: de proliferação de documentos normativos e legais. Isso permitirá à abordagem proposta colaborar com as tarefas de busca e ciência de novos documentos normativos e legais. Por outro lado, consideramos de menor relevância a atividade "Descartar conteúdo", indicada por poucos autores do modelo. Para o primeiro momento - disponibilização e implementação da abordagem -, os principais são a carga (upload) e a geração contínua de informações provenientes de campo: metadados de leis e normas, inclusive das mais recentes, bem como a aferição de uso delas (citações para deferir e citações para indeferir) para os diferentes tipos de solicitação. Informações excedentes, abrangendo metadados e aferições de conteúdos não mais válidos do ponto de vista legal e normativo, podem ser tratadas em um segundo 
momento, pós-implementação e difusão da abordagem. Assim, serão trabalhadas seis atividades do processo de gestão da informação contextualizadas para o PAEPOP: identificar conteúdo, obter, distribuir, utilizar, aprender com o uso e contribuir. Essas seis atividades estão descritas nos subitens a seguir. No sétimo e último subitem desta seção, são descritas as principais tecnologias (softwares) e padrões tecnológicos (protocolos) que suportam atividades similares no contexto acadêmico-científico.

\section{Atividade: identificar conteúdo pertinente aos interesses do analista}

O funcionário público que tem como principal função a análise e emissão de parecer é responsável por ter ciência e compreensão do conjunto de leis, normas e portarias pertinentes à sua função (Brasil, 1999). A identificação de novas leis, portarias e normas se dá pela leitura do jornal oficial, publicado diariamente por governo federal brasileiro, denominado de Diário Oficial. Publicações análogas também ocorrem nas esferas dos Estados da República Federativa do Brasil, bem como na maioria dos municípios. Para agilizar a identificação de novos documentos legais de interesse, pode-se adotar a mesma prática corrente entre os pesquisadores do ambiente acadêmico-científico: subscrição de journals e de repositórios que os distribuem. Os pesquisadores configuram pesquisa automática ("robôs") nos repositórios de journals de sua área de interesse e definem a periodicidade da pesquisa e os critérios de pesquisa, permitindo combinação entre eles, por meio de operadores lógicos e meio de notificação do retorno da pesquisa (geralmente e-mail), além da informação a ser transmitida (artigo e/ou referência e/ou resumo e/ou texto completo do artigo). Dessa forma, os pesquisadores são informados sobre a ocorrência de novas publicações que atendam aos seus interesses de pesquisa.

Nessa perspectiva, há a necessidade de as casas de lei e normas, nas diferentes esferas (federal, estadual e municipal), disponibilizarem novos conteúdos por meio de repositório de conteúdo, instrumentados com algoritmos de taxionomia para classificação automática de novos documentos ou de novas versões de documentos já existentes. Esses ambientes devem permitir o cadastramento de analistas de órgãos públicos para que eles configurem e registrem mecanismos de busca automática, segundo os temas de interesse de cada analista. A diversidade e o detalhamento dos descritores disponíveis aos analistas para definição dos critérios de busca impactam diretamente no valor percebido pelos usuários. Daí a importância de cada grupo de profissionais, com interesse em determinado assunto, envolver-se no desenvolvimento e na manutenção da árvore taxionômica a ser utilizada.

Atividade: obter conteúdo pertinente aos interesses do analista

Os textos de leis, normas e portarias apresentam uma estrutura formal com o propósito de atender a uma série de formalidades necessárias segundo a lei: propósito de sua existência, para quem se destina, como se aplica, quando se aplica, entre outras estruturas do documento. Para o dia a dia do exercício da função do analista, esse conteúdo pode não ser prático para o pronto uso. Assim como os pesquisadores destacam partes dos textos e realizam inserções de exemplos e interpretações, seja com anotações no pa- 
pel, seja com inserção de comentários em versões digitais dos documentos, os analistas de órgãos públicos devem ter a mesma demanda atendida. Assim é importante ao analista a posse do arquivo contendo o conteúdo digital, seja na nuvem da Internet, seja no hard-disk de seu computador. Dessa forma, ele terá a possibilidade de realizar grifos e anotações ao longo do texto.

Outro aspecto associado à obtenção de conteúdo é permitir o vínculo de documentos que expliquem ou complementem as ideias que julgar necessárias, por exemplo, vinculando documentos legais a mapas visuais explicativos ou mesmo arquivos contendo exemplos de aplicação da lei. Esses procedimentos são recursos empregados pelos trabalhadores da informação para 0 entendimento de textos, bem como para recuperação rápida da compreensão deles se necessário, após um longo período sem contato e aplicação das leis e normas explicitadas no documento.

Os pesquisadores coletam não apenas arquivos com conteúdo, mas também seus metadados, registrando-os em base de referências bibliográficas pessoais. Eles importam ou digitam os metadados dos conteúdos relevantes no sistema gerenciador de referências pessoais do pesquisador (i.e.: EndNotes, Mendeley, RefWorks, SciRef etc.). Esse é um outro aspecto importante para afirmar que o trabalhador da informação obteve efetivamente um novo conteúdo: ter os metadados dos documentos que precisam ser conhecidos, citados e referenciados. Para isso é necessário que as casas de lei brasileiras adotem protocolos universalmente aceitos para estrutura de dados de documentos, ou seja, os repositórios dessas entidades devem adotar padrões modernos, como o Dublin Core Metadata Iniciative (DCMI), que permitirá que os analistas de órgãos públicos importem os metadados de documentos para sua estação de trabalho, mais especificamente para o banco de dados do sistema gerenciador de referências pessoais.

\section{Atividade: distribuir conteúdo}

No ambiente acadêmico-científico, a principal distribuição de conhecimento científico ocorre por meio de artigos publicados em journals. Além do ambiente digital e físico (edição impressa) desse veículo, torna-se cada vez mais importante a distribuição via repositórios, por permitirem busca simultânea e integrada a vários journals de uma área. A distribuição individual e pontual também pode ocorrer por meio de ambientes de redes virtuais voltadas à comunidade de pesquisadores, por exemplo: o Research Gate. Independentemente das ferramentas de redes sociais, todo artigo científico apresenta o e-mail dos autores, para facilitar o contato e distribuição de conteúdo entre os pesquisadores.

No contexto das normas e leis pertinentes às atividades dos analistas de órgãos públicos, compreende-se como fundamental que as casas de lei e demais órgãos que gerem políticas e normas publiquem seus conteúdos em ambientes tecnológicos como os repositórios digitais ou outras tecnologias voltadas à gestão de conteúdo. Esses ambientes devem proporcionar facilidades de busca por diferentes metadados e metainformações. Dessa forma, esses ambientes devem realizar captura automática de metadados e metainformações no ato da carga (upload) e 
inserção de novos documentos no repositório do órgão público. Para o aprimoramento dessa função, a suíte de softwares associado ao repositório de conteúdo pode abranger uma diversidade de algoritmos como os geradores de resumo (summarizers) e identificadores de palavras-chave e temas de classificação (taxionomy softwares).

Atividade: utilizar conteúdo para fundamentação de pareceres

A identificação do uso de documentos científicos, no contexto acadêmico-científico, caracteriza-se pelos atos de citar e referenciar documentos externos. Os principais indicadores da academia-científica para mensuração do uso de determinado conhecimento científico, como o impact fator ou $\mathrm{H}$-index, utilizam-se da contagem de citações feitas aos documentos científicos. No contexto dos analistas de órgãos públicos se aplica a mesma lógica. Eles devem citar as leis e as normas empregadas para fundamentar o raciocínio lógico desenvolvido durante a fase de análise e, consequentemente, constituirá e suportará o conteúdo do parecer emitido pelo analista.

No ambiente acadêmico-científico, o pesquisador utiliza o sistema gerenciador de referências para realizar pesquisa e recuperação de metadados de documentos cadastrados pelo pesquisador, bem como para a redação automática de textos necessários à citação e referência. Quando o sistema gerenciador está integrado ao editor de texto, o processo de citação e referência fica simples e rápido. Estando no editor de texto, desenvolvendo um documento científico, basta ao pesquisador posicionar o cursor na posição em que deseja inserir a citação e clicar na fun- ção "inserir citação", disponível no menu de opções do próprio editor de texto. Feito isso, aparecerá uma tela de pesquisa apresentando todos os documentos cadastrados no sistema gerenciador de referências pessoal do analista. Ao selecionar um documento de determinada pasta (subtemas de interesse), o sistema gerenciador de referências transmitirá seus metadados para o editor de texto, que construirá o texto da citação no local do cursor, bem como o texto de referência ao final do documento. Tanto a citação quanto a referência podem ser formatados automaticamente conforme o padrão selecionado pelo pesquisador no sistema gerenciador de referências.

Dessa forma, observa-se a importância de os analistas de órgãos públicos terem disponível para uso um sistema gerenciador de referências integrado ao ambiente de redação do parecer. $O$ cadastramento por importação de metadados de leis e normas disponíveis nos repositórios das casas de lei evitará erros de digitação e agilizará o processo de obtenção, gerando o insumo necessário à inserção automática de citação no parecer em elaboração, bem como o desenvolvimento automático da lista de referências.

Atividade: aprender a partir da análise do uso de conteúdos

$\mathrm{Na}$ academia-científica, a prática de identificação e contagem de citações realizadas em documentos científicos são extremamente importantes à aprendizagem dos pesquisadores e refletem diretamente no processo de geração de conhecimento científico. Os indicadores bibliométricos permitem que os pesquisadores tenham ciência dos temas, teorias e paradigmas emergentes, como também 
dos que estão em declínio; permitem identificar os principais autores e journals nos diversos temas e subtemas; permitem identificar a rede de pesquisadores, bem como os conceitos que suportam o desenvolvimento de novos conhecimentos científicos. O uso efetivo de citações e referências nos pareceres de analistas de órgãos públicos permitirá o desenvolvimento de indicadores e de análises que podem colaborar com a autoaprendizagem de cada analista, bem como dos que atuam no desenvolvimento $e$ na atualização de leis e normas.

Para contextualizar as vantagens do monitoramento contínuo de citações em pareceres, pode-se considerar um analista desenvolvendo o exame detalhado de uma solicitação de licença ambiental para uma área com presença de fauna silvestre nativa. Nessa proposta, o trabalho essencial da análise pode ser auxiliado de diversas maneiras. O analista pode, por exemplo, pesquisar em quantos pareceres uma determinada norma foi citada para a negação de licença ambiental envolvendo os temas "supressão de vegetação nativa" e "fauna silvestre nativa," ou ainda, as normas empregadas em pareceres envolvendo os mesmos temas, porém com o parecer favorável ao solicitante.

Atividade: contribuir para a evolução do conteúdo

$\mathrm{Na}$ academia, é comum acompanhar por meio das citações a documentos o desenvolvimento de um tema ou assuntos por países, por centros de pesquisa ou instituições, e por pesquisadores. No contexto dos órgãos públicos, o acompanhamento de citações a documentos permite a identifi- cação de citações a determinado documento por agente público (analista), por órgão público ou mesmo regiões do Estado ou da federação. Constitui-se em fonte para identificação do não uso ou do uso excessivo de determinados documentos legais e normativos. Esse acompanhamento permite a identificação, por exemplo: dos principais usuários a serem consultados por ocasião da necessidade de alteração de determinada lei ou norma; dos documentos que não recebem citação há muito tempo e devem ser averiguados se já não fazem mais sentido perante a sociedade atual e se necessitam ser descartados ou atualizados.

Tecnologias de softwares e protocolos para o suporte das atividades

Uma vez descritas as atividades do PAEPOP, pode-se destacar as tecnologias capazes de suportar e automatizar as funções mais críticas do processo. O Quadro 1 apresenta categorias de tecnologias já existentes, tanto de softwares quanto de protocolos de comunicação, disponíveis na forma de open software e por aquisição de licença de uso. Essas tecnologias cobrem as funções centrais de cinco das atividades do PAEPOP; a única função central não atendida por essas tecnologias é a identificação e a contabilização de documentos citados para fundamentação de cada parecer, associada à atividade "Utilizar conteúdo". Nesse aspecto, o algoritmo a ser desenvolvido deve buscar por conjuntos de caracteres (strings) presentes no texto da fundamentação que represente a citação, bem como obter, na lista de referências, os textos relacionados à referência segundo as normas da Associação Brasileira de Normas Técnicas (ABNT). 
Obviamente as perspectivas em potencial da abordagem descrita neste capítulo são mais amplas do que as funcionalidades discutidas nesta pesquisa. Os especialistas em gestão pública, consultados por esta pesquisa, foram questionados e analisaram a abordagem proposta, exclusivamente em termos da capacidade dela em apoiar o desenvolvimento das análises e emissão de parecer, bem como o apoio aos gestores no monitoramento e controle da qualidade desses pareceres. O descritivo da abordagem apresentada aos especialistas, no primeiro instrumento de interação (disponível em: <www.datadelphi.com>), concentrou-se exclusivamente nesses dois momentos centrais do PAEPOP.

\section{DISCUSSÃO DE AÇÕES PARA MITIGAR RESISTÊNCIAS À ABORDAGEM}

Kim (2015) destaca que as dimensões mais complexas para predizer as tendências associadas à absorção tecnológica são as associadas a questões sociais, culturais, políticas e econômicas. Essa afirmação é coerente com o cenário descrito por Gregor e Hevner (2013) para inovação por exaptation. Conforme a Figura 1, nesse contexto há: alto domínio da solução, ou seja, das tecnologias envolvidas, e baixo domínio da natureza do problema, isto é, do ambiente em que a abordagem será utilizada. Cabe destacar que há mais de uma década a academia-científica desenvolve e aplica softwares para o processo de gestão de citações e referências, bem como desenvolve protocolos para agilizar a guarda, pesquisa e recuperação de documentos. Considerando a maturidade atual das tecnologias associadas à abordagem em discussão, tem-se que os maiores riscos e incertezas da abordagem proposta estão atrelados às questões humanas e não às tecnológicas. Dessa forma, concentramos as questões analisadas pela técnica Policy Delphi em torno das dimensões culturais, políticas, sociais e econômicas.

Entre as dimensões humanas associadas à abordagem em estudo, um aspecto central refere-se às possíveis fontes de resistência, tema recorrente em termos de introdução de novas tecnologias. No primeiro instrumento de interação com os especialistas em gestão pública, uma das questões identificou as propostas de ações para inibir possíveis fontes de resistência dos analistas à abordagem, objeto central desta pesquisa. Os especialistas em gestão pública, com experiência no PAEPOP, indicaram 37 proposições de combate à resistência. Após as atividades de análise e consolidação delas, obtiveram-se 21 proposições, distribuídas em 5 categorias, conforme descrito no Quadro 4. 
Quadro 4. Proposições de ações para inibir a resistência dos analistas à abordagem

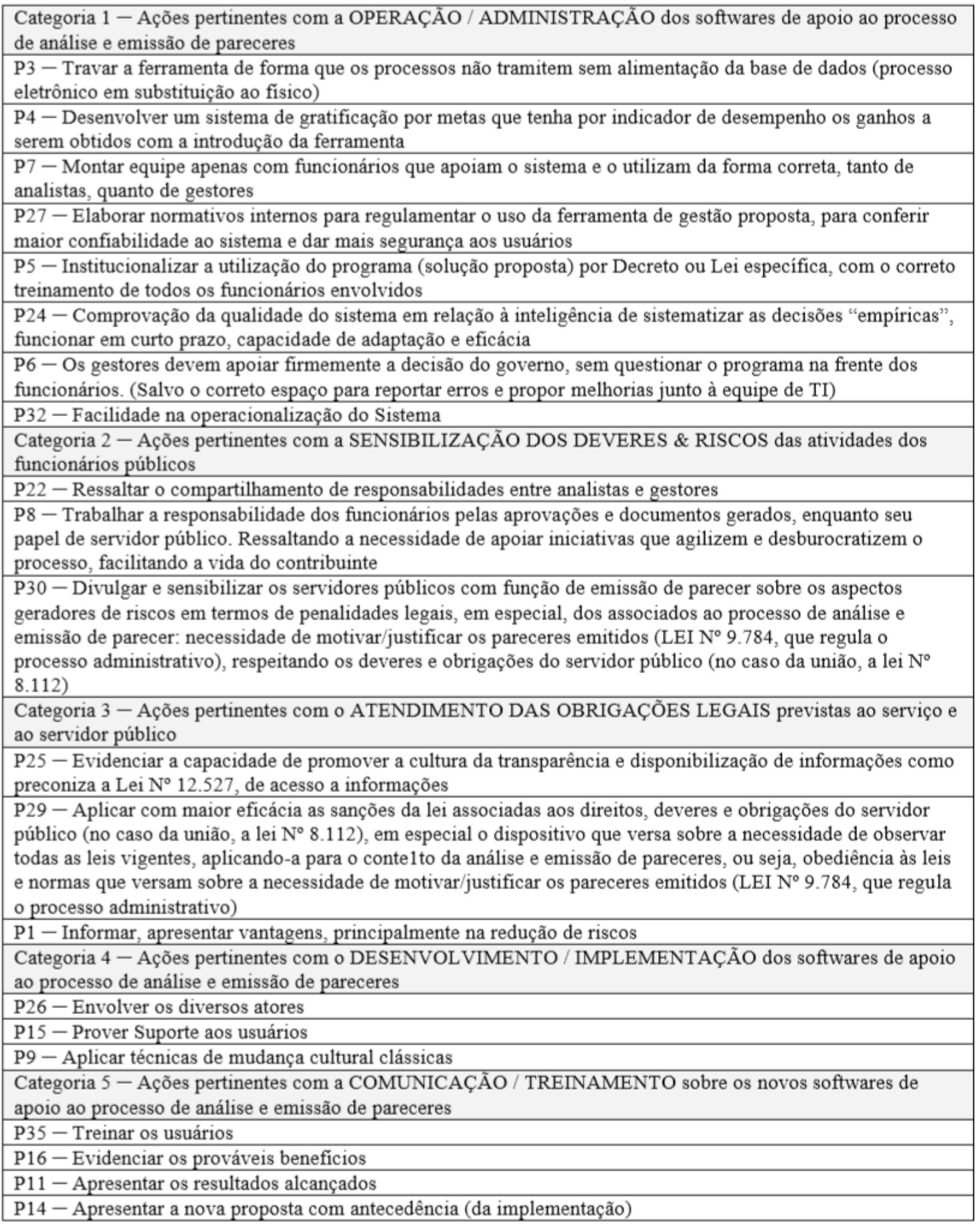

Quanto à utilidade da abordagem, os especialistas em gestão pública a percebem como útil, tanto aos analistas que realizam a análise e emissão de parecer, quanto aos gestores que supervisionam e administram o
PAEPOP. Observou-se alto nível de consenso entre os especialistas em gestão pública para essas duas percepções, ambas favoráveis à implementação e operacionalização da abordagem. Os especialistas apontaram, 
também, para o risco de resistência ao uso da abordagem por parte dos analistas responsáveis pela análise e emissão de parecer junto aos órgãos públicos. Identificou-se um nível moderado de consenso entre os especialistas para essa percepção, que é de sentido contrário, negativo à implementação e operacionalização da abordagem. A análise de consenso para as respostas do grupo de especialistas para os três tópicos está descrita na Tabela 1.

Tabela 1. Análise de consenso das questões analíticas do primeiro instrumento

\begin{tabular}{|c|c|c|c|c|c|c|c|}
\hline & 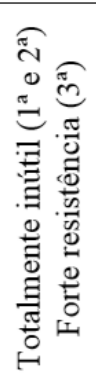 & 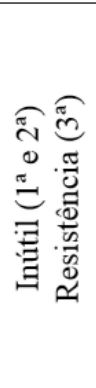 & 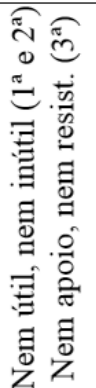 & 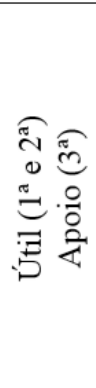 & 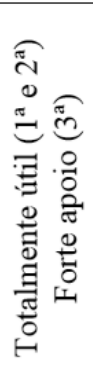 & 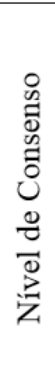 & 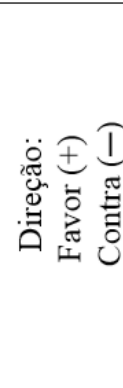 \\
\hline $\begin{array}{l}1^{\text {a }} \text { Questão analítica - do nível de } \\
\text { apoio do artefato aos Analistas } \\
\text { durante as atividades de análise e } \\
\text { emissão de parecer }\end{array}$ & $0 \%$ & $0 \%$ & $0 \%$ & $54 \%$ & $46 \%$ & $\stackrel{\ominus}{\gtrless}$ & + \\
\hline $\begin{array}{l}2^{\text {a }} \text { Questão analítica - do nível de } \\
\text { apoio do artefato aos Gestores no } \\
\text { monitoramento e controle da } \\
\text { qualidade dos pareceres emitidos }\end{array}$ & $0 \%$ & $0 \%$ & $0 \%$ & $54 \%$ & $46 \%$ & $\stackrel{\varrho}{\longleftarrow}$ & + \\
\hline $\begin{array}{l}3^{\text {a }} \text { Questão analítica - do nível de } \\
\text { receptividade dos analistas de } \\
\text { órgãos públicos ao uso e aos } \\
\text { resultados do artefato }\end{array}$ & $20 \%$ & $50 \%$ & $20 \%$ & $20 \%$ & $0 \%$ & 乎 & - \\
\hline
\end{tabular}

As percepções dos especialistas consultados, considerando a abordagem como útil às atividades centrais dos analistas e dos gestores que atuam junto ao PAEPOP, agregadas à detecção do risco de possíveis fontes de resistência, justificam o levantamento e discussão de proposições de ações para inibir possíveis fontes de resistência à implementação e operacionalização da abordagem. Esse tema foi explorado na segunda interação com o grupo de especialistas. As 21 proposições identificadas na primeira interação (ver Quadro 4) foram apresentadas aos especialistas, solicitando-se que eles as analisassem perante duas dimensões: a importância da proposição ao combate a possíveis resistências e a exequibilidade de implementação da proposição sugerida. A Tabela 2 apresenta a análise de consenso para os resultados obtidos para essas duas dimensões, para cada uma das 21 proposições analisadas pelos especialistas, após dois ciclos de interações. Das 21 proposições, 6 alcançaram níveis de consenso importantes de serem observados, tendo as suas duas dimensões alcançado alto consenso ou pelo menos uma das duas com alto consenso e a outra com consenso moderado. As seis pro- 
posições estão apresentadas na parte superior da Tabela 2, destacadas em negrito; a análise desses resultados é realizada nos parágrafos a seguir.

Tabela 2. Análise de consenso das 21 proposições sugeridas pelos especialistas

\begin{tabular}{|c|c|c|c|c|c|c|c|c|c|c|c|c|c|c|}
\hline \multirow[b]{2}{*}{ 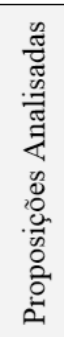 } & \multicolumn{7}{|c|}{$\begin{array}{c}\text { IMPORTÂNCIA/CAPACIDADE } \\
\text { da proposição em termos de reduzir resistências }\end{array}$} & \multicolumn{7}{|c|}{$\begin{array}{c}\text { VIABILIDADE/EXEQUIBILIDADE } \\
\text { da proposição em termos de ser implementada }\end{array}$} \\
\hline & 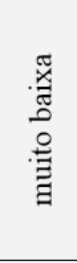 & . & 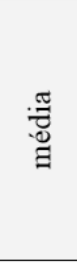 & $\stackrel{\frac{\pi}{\pi}}{\pi}$ & $\begin{array}{l}\frac{\pi}{\pi} \\
\stackrel{0}{0} \\
\stackrel{\Xi}{\Xi}\end{array}$ & 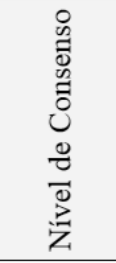 & 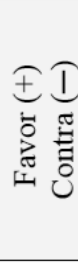 & 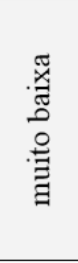 & 荧 & 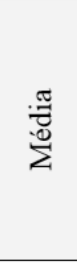 & $\frac{\pi}{\pi}$ & 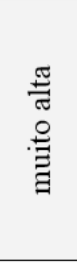 & 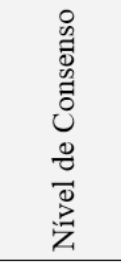 & 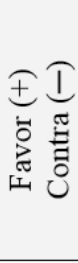 \\
\hline P1 & & & $20 \%$ & $70 \%$ & $10 \%$ & alto & + & & & $20 \%$ & $50 \%$ & $30 \%$ & alto & + \\
\hline P15 & & & $20 \%$ & $40 \%$ & $40 \%$ & alto & + & & & $10 \%$ & $70 \%$ & $20 \%$ & alto & + \\
\hline P32 & & $10 \%$ & & $50 \%$ & $40 \%$ & alto & + & & $10 \%$ & $20 \%$ & $50 \%$ & $20 \%$ & modera & + \\
\hline P35 & $10 \%$ & & & $50 \%$ & $40 \%$ & alto & + & $10 \%$ & & $20 \%$ & $30 \%$ & $40 \%$ & modera & + \\
\hline P27 & & $20 \%$ & $10 \%$ & $30 \%$ & $40 \%$ & modera & + & & & $10 \%$ & $60 \%$ & $30 \%$ & alto & + \\
\hline P30 & & $10 \%$ & $20 \%$ & $60 \%$ & $10 \%$ & modera & + & & & $20 \%$ & $60 \%$ & $20 \%$ & alto & + \\
\hline P3 & $10 \%$ & & $30 \%$ & $40 \%$ & $20 \%$ & baixo & + & & & & $60 \%$ & $40 \%$ & alto & + \\
\hline $\mathrm{P} 4$ & & $10 \%$ & $10 \%$ & $50 \%$ & $30 \%$ & alto & + & $20 \%$ & $30 \%$ & & $40 \%$ & $10 \%$ & não 1 & \\
\hline P5 & & & $40 \%$ & $40 \%$ & $20 \%$ & baixo & + & & & $10 \%$ & $40 \%$ & $50 \%$ & alto & + \\
\hline P6 & $10 \%$ & $30 \%$ & $20 \%$ & $30 \%$ & $10 \%$ & \multicolumn{2}{|c|}{ não há } & $10 \%$ & $10 \%$ & & $70 \%$ & $10 \%$ & alto & + \\
\hline P7 & $10 \%$ & $30 \%$ & $30 \%$ & $10 \%$ & $20 \%$ & \multicolumn{2}{|c|}{ não há } & $20 \%$ & $30 \%$ & $10 \%$ & $30 \%$ & $10 \%$ & não 1 & \\
\hline $\mathrm{P} 8$ & $10 \%$ & $10 \%$ & $20 \%$ & $40 \%$ & $20 \%$ & baixo & + & & $20 \%$ & $20 \%$ & $50 \%$ & $10 \%$ & baixo & + \\
\hline P9 & & & $20 \%$ & $60 \%$ & $20 \%$ & alto & + & & $20 \%$ & $30 \%$ & $30 \%$ & $20 \%$ & não 1 & \\
\hline P11 & & & $30 \%$ & $40 \%$ & $30 \%$ & modera & + & & & $40 \%$ & $40 \%$ & $20 \%$ & baixo & + \\
\hline P14 & & $10 \%$ & $30 \%$ & $30 \%$ & $30 \%$ & baixo & + & & & $10 \%$ & $60 \%$ & $30 \%$ & alto & + \\
\hline P16 & $10 \%$ & & $20 \%$ & $50 \%$ & $20 \%$ & modera & + & & $10 \%$ & $20 \%$ & $60 \%$ & $10 \%$ & modera & + \\
\hline $\mathrm{P} 22$ & $10 \%$ & & $40 \%$ & $40 \%$ & $10 \%$ & \multicolumn{2}{|c|}{ não há } & & $30 \%$ & $20 \%$ & $40 \%$ & $10 \%$ & \multicolumn{2}{|c|}{ não há } \\
\hline $\mathrm{P} 24$ & & $10 \%$ & $40 \%$ & $20 \%$ & $30 \%$ & \multicolumn{2}{|c|}{ não há } & $10 \%$ & $10 \%$ & $10 \%$ & $40 \%$ & & \multicolumn{2}{|c|}{ não há } \\
\hline $\mathrm{P} 25$ & & $20 \%$ & $40 \%$ & $30 \%$ & $10 \%$ & \multicolumn{2}{|c|}{ não há } & & $10 \%$ & $30 \%$ & $50 \%$ & $10 \%$ & baixo & + \\
\hline $\mathrm{P} 26$ & & & $30 \%$ & $20 \%$ & $50 \%$ & modera & + & & $10 \%$ & $40 \%$ & $20 \%$ & $30 \%$ & \multicolumn{2}{|c|}{ não há } \\
\hline P29 & & & $40 \%$ & $30 \%$ & $30 \%$ & baixo & + & & $10 \%$ & $40 \%$ & $40 \%$ & $10 \%$ & \multicolumn{2}{|c|}{ não há } \\
\hline
\end{tabular}

Duas proposições apresentaram alto consenso entre os especialistas quanto às duas dimensões analisadas: alta importância ao combate de resistências à utilização da abordagem e alta exequibilidade. A primeira delas: "P1 - Informar, apresentar vantagens, principalmente na redução de riscos" está associada à ação de evidenciar aos analistas, responsáveis pela análise e emissão de parecer, a capacidade da abordagem de mitigar riscos associados aos seus pareceres, alertando-os, por exemplo, a ausência de fundamentação ou de fundamentação bastante distinta das séries históricas praticadas até então para a díade tipo de solicitação analisada e tipo de decisão atribuída. A contrapartida do analista, para isso, é a utilização da abordagem (técnicas e softwares) para auxiliar na realização de atividades, que, segundo as leis que regem a função dos analistas públicos, devem ser realizadas de qualquer forma, com ou sem o apoio da abordagem. A outra proposição com as duas dimensões apresentando alto consen- 
so refere-se à utilização da abordagem, em especial de apoio à utilização dos softwares necessários, caracterizada pela proposição "P15 - Prover suporte aos usuários". A ideia é permitir a superação de qualquer dificuldade operacional encontrada durante a utilização dos softwares e técnicas associadas à abordagem.

A abordagem proposta deve combater riscos já conhecidos, porém sem gerar outros, por exemplo, ter a certeza de que os softwares e técnicas devem ser utilizados, sem objeções ou sanções futuras aos usuários. Para isso, os especialistas indicaram, por outra proposição, a necessidade de normatizar o uso da abordagem em suporte às atividades do PAEPOP: "P27 - Elaborar normativos internos para regulamentar 0 uso da ferramenta de gestão proposta, para conferir maior confiabilidade ao sistema e dar mais segurança aos usuários". Essa proposição foi considerada pelos especialistas como de alta capacidade de exequibilidade e moderada capacidade de inibir resistências quanto ao uso da abordagem, conforme se observa na Tabela 2. Com análise igual, de alta exequibilidade e moderada capacidade de redução de resistências, temos a proposição "P30 - Divulgar e sensibilizar os servidores públicos com função de emissão de parecer sobre os aspectos geradores de riscos em termos de penalidades legais, em especial, dos associados ao processo de análise e emissão de parecer: necessidade de motivar/justificar os pareceres emitidos (Lei 9.784, que regula o processo administrativo), respeitando os deveres e as obrigações do servidor público (no caso da União, a Lei 8.112)". A demanda atendida por essa proposição é a sensibilização dos deveres e riscos daqueles responsáveis pela análise e emissão de parecer em órgãos públicos.

Como proposições identificadas pelos especialistas como possuidoras de alta capacidade de reduzir resistências e de moderada exequibilidade, temos: "P32 - Facilidade na operacionalização do Sistema" e "P35 - Treinar os usuários". Ambas refletem diretamente a capacidade de os analistas utilizarem a abordagem, ou seja, melhorar ao máximo possível a relação custo-benefício da utilização da abordagem em prol do analista. Assim, das seis proposições identificadas como relevantes pelos especialistas, três são bastante específicas para o contexto analisado: P1, P27 e P30. As outras três proposições identificadas como relevantes (P15, P32 e P35), embora importantes, são mais genéricas e passíveis de serem identificadas e aplicadas em qualquer contexto de implementação e utilização de sistema de informação reconhecido como importante à organização.

As contribuições científicas no paradigma da DSR apresentam o processo de geração de conhecimento em diversos ciclos de aprimoramento do projeto da abordagem, trabaIhando conjuntamente com conhecimento descritivo e prescritivo (Gregor \& Hevner, 2013). Essa pesquisa pode ser compreendida como uma prévia ao primeiro ciclo com a caracterização inicial da abordagem a ser aplicada ao PAEPOP Os trabalhos se concentraram nos aspectos descritivos voltados à segurança dos analistas executores das análises, em termos de assegurar o uso da abordagem proposta e combater possíveis fontes de resistência à sua adoção. Ao mesmo tempo, trabalhou alguns aspectos do conhecimento prescritivo da abordagem, descrevendo possíveis algoritmos a serem utilizados pelas seis atividades do proces- 
so (descritos nas seis primeiras subseções do capítulo Descrição da Abordagem), bem como os produtos tecnológicos, como padrões tecnológicos e famílias de softwares (descritos na última subseção do capítulo Descrição da Abordagem) úteis à operacionalização da abordagem.

A abordagem proposta não está desenvolvida ou mesmo totalmente especificada para futuro desenvolvimento, em especial em termos de integração dos diversos algoritmos (softwares) em torno das atividades, configurando-se como uma limitação da presente pesquisa. A implementação e o teste da abordagem de apoio ao PAEPOP, conforme descritos no paradigma de pesquisa DSR, podem ocorrer tanto no contexto individual, como ocorre com as propostas de personal knowledge management (Pauleen, 2009), quanto no departamental, organizacional ou em redes de organizações. Quanto maior o escopo do contexto de aplicação, maiores os retornos e os desafios sociais e tecnológicos. Como continuidade desta pesquisa, são recomendados a implementação inicial e o teste da abordagem no contexto departamental de um órgão público. Imaginando a facilidade em termos de localização desse espaço público, sugere-se a esfera municipal, considerando que o Brasil possui mais de 5.500 municípios. Nas prefeituras, as secretarias de obras e finanças configuram-se como espaços intensivos da prática de análise e emissão de pareceres.

\section{REFERÊNCIAS}

Allen, M., \& Andriani, P. (2013). Diversity, interconnectivity and sustainability. In: J. Bogg, R. Geyer (Eds.) Complexity, Science and Society. pp. 11-32. Oxford, UK: Radcliffe
Publishing.

Amaral, L., Olenike, E., \& Amaral, F. (2013). Quantidade de normas editadas no Brasil: 25 anos de Constituição Federal de 1988. Curitiba: Instituto Brasileiro de Planejamento Tributário.

Andriani, P., \& Cohen, J. (2013). From exaptation to radical niche construction in biological and technological complex systems. Complexity, 18(5), 7-14.

Argyris, C. (1971). Management Information Systems: The challenge to rationality and emotionality. Management Science, 17(6), B-275-B-292.

Barthol, R. P., Vasarhelyi, M. A. (1975). Resistência à implantação de sistemas de informação gerencial. Revista de Administração de Empresas, 15(2), 27-34.

Brasil. (1999, fev. 1). Lei 9.784, de 29 de janeiro de 1999. Diário Oficial da República Federativa do Brasil, Poder Legislativo, Brasília, DF.

Brasil. (2010, out. 28). Superior Tribunal Federal. Súmula № 7, Recurso especial $\mathrm{n}$. 1.148.460 - PR (2009/0030518-0). Diário da Justiça Eletrônico, Curitiba, PR.

Brazilian tax litigation booms as economy grows. (2011). International Tax Review, 22(9), 31.

Cardoso, A. M. (2002). Neoliberalism, Unions, and Socio-Economic Insecurity in Brazil. Labour, Capital \& Society, 35(2), 282-316.

Choo, W. (2011). A organização do conhe- 
cimento (3. ed.). São Paulo: Editora Senac.

Critcher, C, \& Gladstone, B. (1998). Utilizing the Delphi Technique in Policy Discussion: a case study of a privatized utility in Britain. Public Administration, 76(3), 431-449.

Danneels, E. (2002). The dynamics of product innovation and firm competences. Strategic Management Journal, 23(12), 10951121.

De Loë, C. (1995). Exploring complex policy questions using the Policy Delphi: a multi-round, interactive survey method. Applied Geography, 15, 53-68.

Dew, N., Sarasvathy, S. D. (2016). Exaptation and niche construction: behavioral insights for an evolutionary theory. Industrial and Corporate Change, 25(1), 167-179.

Duarte, A., \& Otavio, C. (2011, Jun. 18). Brasil faz 18 leis por dia, e a maioria vai para o lixo. O Globo, Rio de Janeiro. Recuperado em 20 set. 2016, dehttp://oglobo.globo.com/ politica/brasil-faz-18-leis-por-dia-a-maioria-vai-para-lixo-2873389\#ixzz4JmNUFeHy

Felker, L. S. (2003). The Iberian Administrative Legacy. Public Administration Quarterly, 27(1/2), 87-114.

Gagliardi, P. (2001). Explorando o lado estético da vida organizacional. In: Clegg, S. R., Hardy, C., Nord, R. Handbook de Estudos Organizacionais. pp. 127-149, São Paulo: Atlas.

Gasparini, D. (2005). Direito Administrativo (10. ed.). São Paulo: Saraiva.
Gregor, S, \& Hevner, R. (2013). Positioning and presenting design science research for maximum impact. MIS Quarterly, 37(2), 337355.

Gregor, S, \& Hevner, R. (2014). The Knowledge Innovation Matrix (KIM): A clarifying lens for innovation. Informing Science: the International Journal of an Emerging Transdiscipline, 17, 217-239.

Grant, M. (1996). Toward a Knowledge-Based Theory of the Firm. Strategic Management Journal, 17, 109-122.

Gupta, S., Davoodi, H., \& Alonso-Terme, R. (1998). Does Corruption Affect Income Equality and Poverty? IMF Working Paper, Washington, DC: International Monetary Fund.

Hevner, A. R., March, S. T., Park, J., \& Ram, $S .(2004)$. Design science in information systems research. MIS Quarterly, 28(1), 75-105.

livari, J. (2007). A paradigmatic analysis of information systems as a design science. Scandinavian Journal of Information Syste$m s, 19(2), 39-64$.

Kim, H-C. (2015). Acceptability engineering: the study of user acceptance of innovative technologies. Journal of Applied Research and Technology, 13(2), 230-237.

Kuechler, B., \& Vaishnavi, V. (2008). Theory development in design science research: anatomy of a research project. European Journal of Information Systems, 17(5), 489504.

Lytras, D., \& Pouloudi, A. (2003). Project management as a knowledge management 
primer: the learning infrastructure in knowledge-intensive organizations: projects as knowledge transformations and beyond. The Learning Organization, 10(4/5), 237-250.

Mathieson, K. (2007). Towards a Design Science of Ethical Decision Support. Journal Of Business Ethics, 76(3), 269-292.

Mathieson, K. (2007). Towards a Design Science of Ethical Decision Support. Journal of Business Ethics, 76(3), 269-292.

Nissen, M., kamel, M., \& Sengupta, K. (2000). Integrated analysis and design of knowledge systems and processes. Information Resources Management Journal, 13, 24-43.

O'Brien, J. A. (2004). Sistemas de informação e as decisões gerenciais na era da Internet. 2. ed. São Paulo: Saraiva.

O'Loughlin, R., \& Kelly, A. (2004). Equity in resource allocation in the Irish health service: a Policy Delphi study. Health Policy, 67(3), 271-280.

Pauleen, D. (2009). Personal knowledge management: putting the "person" back into the knowledge equation. Online Information Review, 33(2), 221-224.

Ribeiro, B. S. (2011). O Excesso de Leis e sua inefetividade social. Âmbito Jurídico, XIV(87). Recuperado de <www.ambito-juridico.com.br/site/index.php?n_link=revista_ artigos_leitura\&artigo_id=9332>.

Rubenstein-montano, B. et al. (2001). A systems thinking framework for knowledge management. Decisions Support Systems
Journal, 31, 5-16.

São Paulo. Lei 10.177, de 30 de dezembro de 1998. Diário Oficial do Estado de São Paulo, Poder Executivo, São Paulo, SP, 31 de dez. 1998.

Simon, H. A. (1996). The Sciences of the artificial. (3 ed.). Cambridge, MA: MIT Press.

Smith, M. (2002). DSpace: An open source institutional repository for digital material. $D$ -Lib Magazine, 8(10).

Srivastava, S. C., Teo, T. S. H., \& Devaraj, S. (2016). You can't bribe a computer: Dealing with the societal challenge of corruption through ICT. MIS Quarterly, 40(2), 511-526.

Teixeira, C. G. (2009). Obrigatoriedade de motivação dos atos administrativos. Âmbito Jurídico, XII(65). Recuperado em 13 abr. 2018, de www.ambito-juridico.com. br/site/index.php?n_link=revista_artigos_ leitura\&artigo_id=6131

Turner, R., \& Cochrane, R. (1993). Goals-and-methods matrix: coping with projects with ill defined goals and/or methods of achieving them. International Journal of Project Management, 11(2), 93-102.

Turoff, M. (1970). The design of a Policy Delphi. Technological Forecasting and Social Change, 2(2), 149-171.

Valente, A., Castellani, T., Larsen, M., \& Aro, R. (2015). Models and Visions of Science -Policy interaction: Remarks from a Delphi study in Italy.Science \& Public Policy, 42(2), 228-241. 